\title{
ORIGINAL ARTICLE Caspase-2-mediated cell death is required for deleting aneuploid cells
}

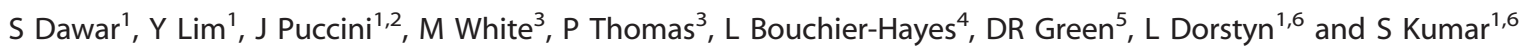

\begin{abstract}
Caspase-2, one of the most evolutionarily conserved of the caspase family, has been implicated in maintenance of chromosomal stability and tumour suppression. Caspase-2 deficient (Casp $2^{-1-}$ ) mice develop normally but show premature ageing-related traits and when challenged by certain stressors, succumb to enhanced tumour development and aneuploidy. To test how caspase- 2 protects against chromosomal instability, we utilized an ex vivo system for aneuploidy where primary splenocytes from Casp $2^{-/-}$ mice were exposed to anti-mitotic drugs and followed up by live cell imaging. Our data show that caspase- 2 is required for deleting mitotically aberrant cells. Acute silencing of caspase- 2 in cultured human cells recapitulated these results. We further generated Casp2 ${ }^{\text {C320S }}$ mutant mice to demonstrate that caspase-2 catalytic activity is essential for its function in limiting aneuploidy. Our results provide direct evidence that the apoptotic activity of caspase-2 is necessary for deleting cells with mitotic aberrations to limit aneuploidy.
\end{abstract}

Oncogene (2017) 36, 2704-2714; doi:10.1038/onc.2016.423; published online 19 December 2016

\section{INTRODUCTION}

Genomic instability, one of the characteristic traits of tumour cells, is often caused by chromosome missegregation or DNA errors arising from replicative, oxidative or oncogenic stress. ${ }^{1,2}$ Genomic instability can either arise from various structural lesions, such as mutations, chromosomal deletions or translocations, or can result from numerical alterations where cells lose or gain copies of whole chromosomes (aneuploidy). ${ }^{3}$ As the most common chromosome abnormality in humans, aneuploidy is the most common chromosome abnormality in humans, is the cause of many congenital birth defects and is found in the majority of solid tumours. ${ }^{4}$ It is also considered a major underlying contributor to cancer onset and prognosis. Aneuploidy arises from aberrant mitotic events, including defects in centrosome number, kinetochore-microtubule attachments, spindle-assembly checkpoint (SAC), chromosome cohesion or telomeres. ${ }^{4}$

Aberrant mitotic arrest mechanisms normally trigger cell death by apoptosis, which is sometimes referred to as mitotic catastrophe. ${ }^{5,6}$ Apoptosis of cells carrying mitotic defects can be induced by inhibition of DNA damage response and cell cycle checkpoint genes. It has been shown to occur in both a p53-dependent and independent manner, such as in Chk2 inhibited syncytia or in polo-like kinase 2 (Plk 2)-depleted cells. ${ }^{6}$ Inhibition of apoptosis can promote pre-mature mitotic exit (mitotic slippage) and cell cycle progression without chromatid segregation. ${ }^{7,8}$ If these aberrant cells are not removed, they can accumulate and acquire additional mutations, a key mechanism leading to aneuploidy, tumorigenesis and antimitotic drug resistance. ${ }^{4,9,10}$

Caspase- 2 is one of the most evolutionarily conserved members of the caspase family. Caspase- 2 is activated following a variety of cellular insults (metabolic imbalance, DNA damage) ${ }^{11}$ and activates other caspases to both initiate and amplify the apoptosis signal. $^{12}$ Recent data suggest that caspase-2-deficient $\left(\right.$ Casp $\left.^{-/-}\right)$ MEFs can readily escape senescence, rapidly immortalise in culture $^{13}$ and show enhanced sensitivity to transformation by oncogenes. ${ }^{14,15}$ In addition, Casp2 $2^{-/-}$MEFs are more resistant to apoptosis induced by microtubule and spindle poisons ${ }^{16}$ and show increased DNA damage following irradiation, ${ }^{13}$ suggesting that Casp2 loss can promote survival of cells with damaged DNA. Although they develop normally, previous studies have established that Casp $^{-/-}$mice show enhanced susceptibility to tumorigenesis promoted by E $\mu M y c$, MMTV/c-neu and K-Ras, ${ }^{14,17-20}$ increased lymphomagenesis in $\mathrm{Atm}^{-/-}$mice, ${ }^{21}$ and diethylnitrosaminemediated hepatocellular carcinoma, ${ }^{22}$ indicating a role for caspase-2 as a tumour suppressor. A common feature of the Casp2 ${ }^{-1-}$ tumours from these mouse models is increased chromosomal instability and aneuploidy. ${ }^{13,14,18,19,21,22}$ These observations suggest that caspase- 2 can protect cells against aneuploidy and tumorigenic potential. Some previous in vitro observations suggest that caspase- 2 has a role in mitotic catastrophe. ${ }^{5}$ Caspase- 2 phosphorylation by Cdk1-cyclin B1 complex has been implicated as one mechanism that can prevent caspase-2 activation and cell death, ${ }^{12}$ thereby promoting mitotic slippage. However, the molecular details that trigger caspase-2 activation during mitotic arrest are not clear, and it is not known if this directly leads to aneuploidy and tumorigenic transformation. It is also unclear whether aneuploidy seen in Casp2 $2^{-/-}$tumours and MEFs is a consequence of caspase- 2 function in promoting apoptosis of mitotically aberrant cells or due to other roles of caspase-2 in cell cycle.

To address this key question, we established an ex vivo system for aneuploidy using primary cells or used a human cell line acutely depleted of caspase-2. Our data show an important role

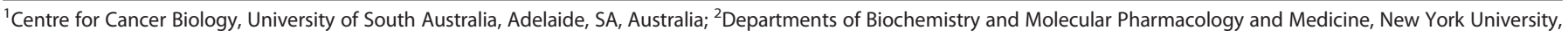

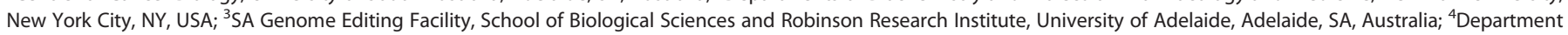

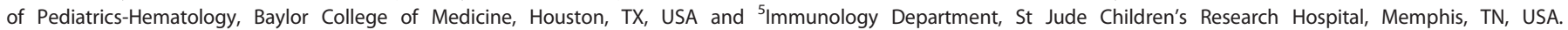
Correspondence: Professor S Kumar, Centre for Cancer Biology, University of South Australia, Frome Road, Adelaide 5001, SA, Australia.

E-mail: sharad.kumar@unisa.edu.au

${ }^{6}$ Co-senior authors.

Received 27 May 2016; revised 6 September 2016; accepted 3 October 2016; published online 19 December 2016
} 
for caspase-2 in limiting aneuploidy by deleting chromosomally unstable cells, at least in part via Bid-mediated apoptosis. We also tested the importance of caspase-2 catalytic activity in deleting chromosomally unstable cells by generating a Casp2 ${ }^{\mathrm{C} 320 \mathrm{~S}}$ mutant mouse. Our results demonstrate that in the absence of caspase- 2 activity, cells with defective mitosis become multinucleated and are able to survive long term. Our work establishes a critical role for caspase-2 in the efficient apoptotic removal of potentially tumorigenic cells and provides a basis for the tumour suppressor function of caspase- 2 .

\section{RESULTS}

Caspase-2 deficient cells are a novel model of aneuploidy

To test how caspase-2 loss might lead to aneuploidy, we utilized a cell system that can monitor aneuploidy directly using the PLK1 inhibitor BI 2536. PLK1 plays a critical role in centrosome maturation in late G2/early prophase and is required for establishment of the mitotic spindle. ${ }^{23,24}$ Inhibition of PLK1 has been shown to cause aneuploidy followed by apoptosis of these aneuploid cells. ${ }^{25}$ As mouse embryonic fibroblasts (MEFs) are highly unstable in culture and cannot be used for such experiments, we established freshly isolated primary mouse splenocytes in cell culture. These cells were stimulated to proliferate by concanavalin A (ConA) for 3 days, supplemented with IL-2 and then exposed to the PLK1 inhibitor BI $2536^{26}$ (PLK1-I) for up to 2 days. The cells were then analysed for viability and aneuploidy by time-lapse microscopy before and after PLK1-I washout (Figure 1a). Control experiments showed that freshly isolated $\mathrm{Casp2}^{-/-}$splenocytes proliferated faster in culture following stimulation with ConA (Supplementary Figure S1a). In addition, while the cell cycle profiles of both WT and Casp2 $2^{-1-}$ splenocytes in culture were indistinguishable, a significantly increased percentage of Casp2 $2^{-/-}$splenocytes were able to cycle through G2/M following PLK1-I-mediated mitotic arrest and drug washout (Supplementary Figure S1b). Karyotypic analysis showed that after several days in culture approximately $15 \%$ of both WT and $\mathrm{Casp}^{-/-}$cells had become aneuploid. However, following PLK1 inhibition and inhibitor washout Casp2 $2^{-/-}$splenocytes were significantly more aneuploid than the WT cells (Figure $1 \mathrm{~b}$ and Supplementary Figure S2a-b). To test if inhibition of caspase activity is sufficient to cause aneuploidy in WT splenocytes, we simultaneously treated cells with a pan-caspase inhibitor and PLK1-I (Figure 1b). Indeed, caspase inhibition was sufficient to significantly increase the proportion of aneuploid WT cells, to the same extent seen in Casp2 $2^{-1-}$ splenocytes treated with PLK1-I. These data also show further enhanced aneuploidy in Casp2 $2^{-/-}$ cells in the presence of a pan-caspase inhibitor, indicating that other caspases may also play a role in limiting aneuploidy. Interestingly, treatment with the microtubule disruptor, Taxol also caused increased aneuploidy in Casp2 $2^{-1-}$ splenocytes (Supplementary Figure S2c). These results indicate that Casp2 deficiency in primary splenocytes promotes increased aneuploidy following mitotic disruption.

Loss of Caspase-2 impairs apoptosis of aneuploid and multinucleated cells

Our previous studies have suggested that caspase- 2 is required for apoptosis in response to agents that disrupt cell division, such as the microtubule stabilizing drug Taxol. ${ }^{16}$ Thus we speculated that increased aneuploidy seen in Casp2 $2^{-1-}$ cells and tumours may be due to the role of caspase- 2 in deleting cells carrying mitotic aberrations. ${ }^{5}$ Indeed, following treatment with PLK1-I, Casp2 ${ }^{-/-}$ splenocytes were more resistant to apoptosis compared to the WT cells (Figure 1c). Similar apoptosis resistance was apparent in Casp2 $2^{-/-}$splenocytes exposed to Taxol or the Eg5 inhibitor,

\section{a}

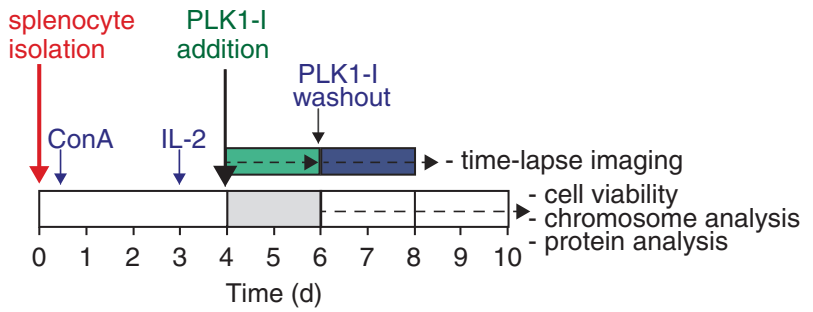

b

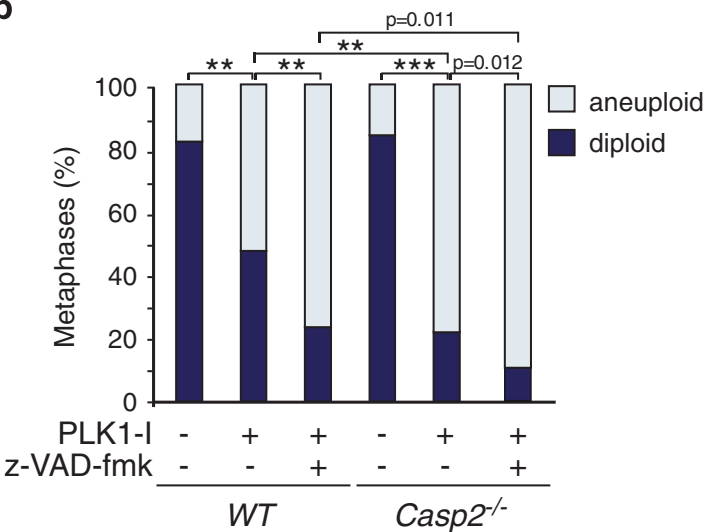

C

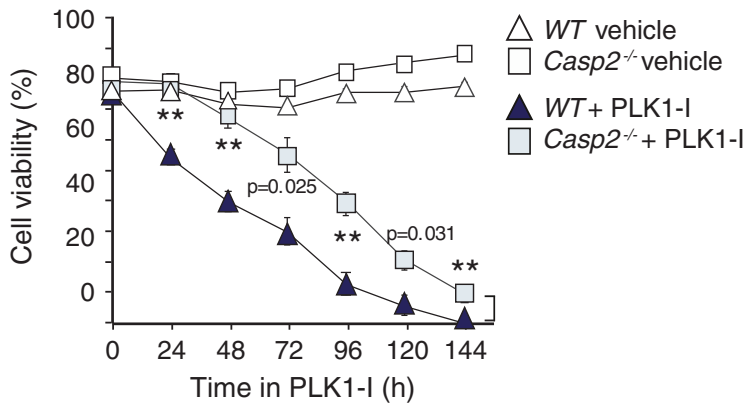

Figure 1. Caspase-2 deficiency enhances aneuploidy and delays apoptosis in primary splenocytes. (a) Protocol used for time-lapse microscopy, cell viability and aneuploidy analysis in primary splenocytes. (b) Quantitation of metaphases showing frequencies of diploid and aneuploid karyotypes in untreated, PLK1 inhibitor (PLK1-I) treated and PLK1-I combined with Z-VAD-fmk (pan caspase inhibitor) treated WT $(n=4)$ and Casp2 $2^{-1-}(n=4)$ splenocytes. A total of 50 metaphase spreads were counted per mouse. $P$ values are indicated with ${ }^{* *} P<0.01,{ }^{* * *} P<0.001, X^{2}$ test. (c) Quantitation of viable cells in WT and Casp2 ${ }^{-1-}$ splenocytes treated with PLK1-I for the indicated time points, determined by trypan blue assay. Data represented as mean \pm s.e.m. from four independent experiments. $P$ values are indicated for PLK1-I treated samples with ${ }^{* *} P<0.01$.

monastrol, which affects mitotic spindle assembly and maintenance $^{27}$ (Supplementary Figure S2d-e).

To investigate whether caspase-2-deficient tumour cells were resistant to PLK1-I-mediated cell death, we treated lymphoma cells from $\mathrm{Atm}^{-/-} / \mathrm{Casp}^{-/-}$mice (as they exhibit increased high grade aneuploidy ${ }^{21}$ ), with PLK1-I over $48 \mathrm{~h}$. $\mathrm{Atm}^{-/-} / \mathrm{Casp}^{-1-}$ lymphoma cells similarly showed increased resistance to cell death compared to their $\mathrm{Atm}^{-1-}$ counterparts (Supplementary Figure S3a). These findings suggest that loss of caspase-2 impedes apoptosis of tumour cells following mitotic arrest. Since a common cause and consequence of aneuploidy is defective regulation and expression of SAC pathway components, ${ }^{10}$ we examined the levels of SAC proteins in $\mathrm{Atm}^{-1-} ; \mathrm{Casp2}^{-1-}$ lymphomas, which showed higher levels of Bub3, Mad2 and 
Cdc20, compared to $\mathrm{Atm}^{-/-}$tumours (Supplementary Figure S3b). We also detected higher levels of these SAC proteins in splenocytes following PLK1-I treatment (data not shown). This may be due to either the increased proliferative capacity of these cells $s^{21}$ and/or increased number of aneuploid cells in the Casp2 $2^{-1-}$ tumour cells. Alternatively, this may indicate an intrinsic yet uncharacterized defect due to caspase-2 deficiency. Together these results suggest that caspase-2 deficiency enhances survival of aneuploid cells, which harbour aberrant levels of SAC proteins that can further contribute to enhanced mitotic progression following caspase-2 loss.

Live imaging of aberrant mitotic arrest and multinucleation in Caspase-2-deficient cells

To examine whether caspase- 2 is required for killing cells during mitosis in vivo, we subjected untreated and PLK1-I-treated splenocytes to live cell imaging. In control experiments there were no apparent differences in cell morphology or cell size between the WT and Casp2 ${ }^{-/-}$splenocytes over time in culture. Both WT and Casp2 ${ }^{-/-}$splenocytes treated with PLK1-I showed aberrant mitotic cells with altered morphology and multiple nuclei (Figures $2 \mathrm{a}$ and b). However, such aberrations were more frequent in Casp2 $2^{-/}$cells compared to the WT cells. A close examination of the imaging data indicated that, while mitotic cell deaths were apparent in both genotypes, more WT splenocytes underwent apoptosis compared to the Casp2 $2^{-/-}$cells (Figure 2c). These observations were even more notable following washout of PLK1-I, with increased survival of multinucleated and abnormally nucleated Casp2 ${ }^{-/-}$cells (Movies 1 and 2). These data suggest that the loss of caspase- 2 results in reduced mitotic cell deaths.

Acute ablation of caspase- 2 enhances survival of multinucleated cells

To further examine if acute loss of caspase-2 (as opposed to chronic absence in cells derived from knockout mice) would result in a similar inability to remove cells with mitotic damage, we used small interfering RNA (siRNA) to silence CASP2 in U2OS cells (Supplementary Figure S4) expressing a green fluorescent protein (GFP)-tagged Histone H2B construct ${ }^{28}$ and also subjected these cells to live cell imaging (Movies 3 and 4). As observed with the Casp2 $2^{-1-}$ splenocytes, there were significantly less apoptotic cells in the CASP2 siRNA transfected U2OS cells at both 24 and $48 \mathrm{~h}$ following addition of PLK1-I compared to the control siRNA treated cells (Figures $3 a$ and $b$; Movies 5 and 6 ). While there were no changes in morphology or cell divisions between the untreated control cells and CASP2 depleted cells (Movies 3 and 4), following PLK1-I washout over a $0-24 \mathrm{~h}$ period, there were significantly more aberrantly shaped multinucleated cells in the CASP2depleted population (Movies 7 and 8). In addition following 24-48 h of PLK1-I washout, while many control cells still died as they attempted to undergo mitosis, CASP2 depletion resulted in increased survival of multinucleated cells and later lead to the accumulation of 'giant' cells with aberrant morphology following $48 \mathrm{~h}$ (Figures $3 \mathrm{c}$ and $\mathrm{d}$ and Movies 7 and 8). Interestingly,

a Time after PLK1-I washout (h)
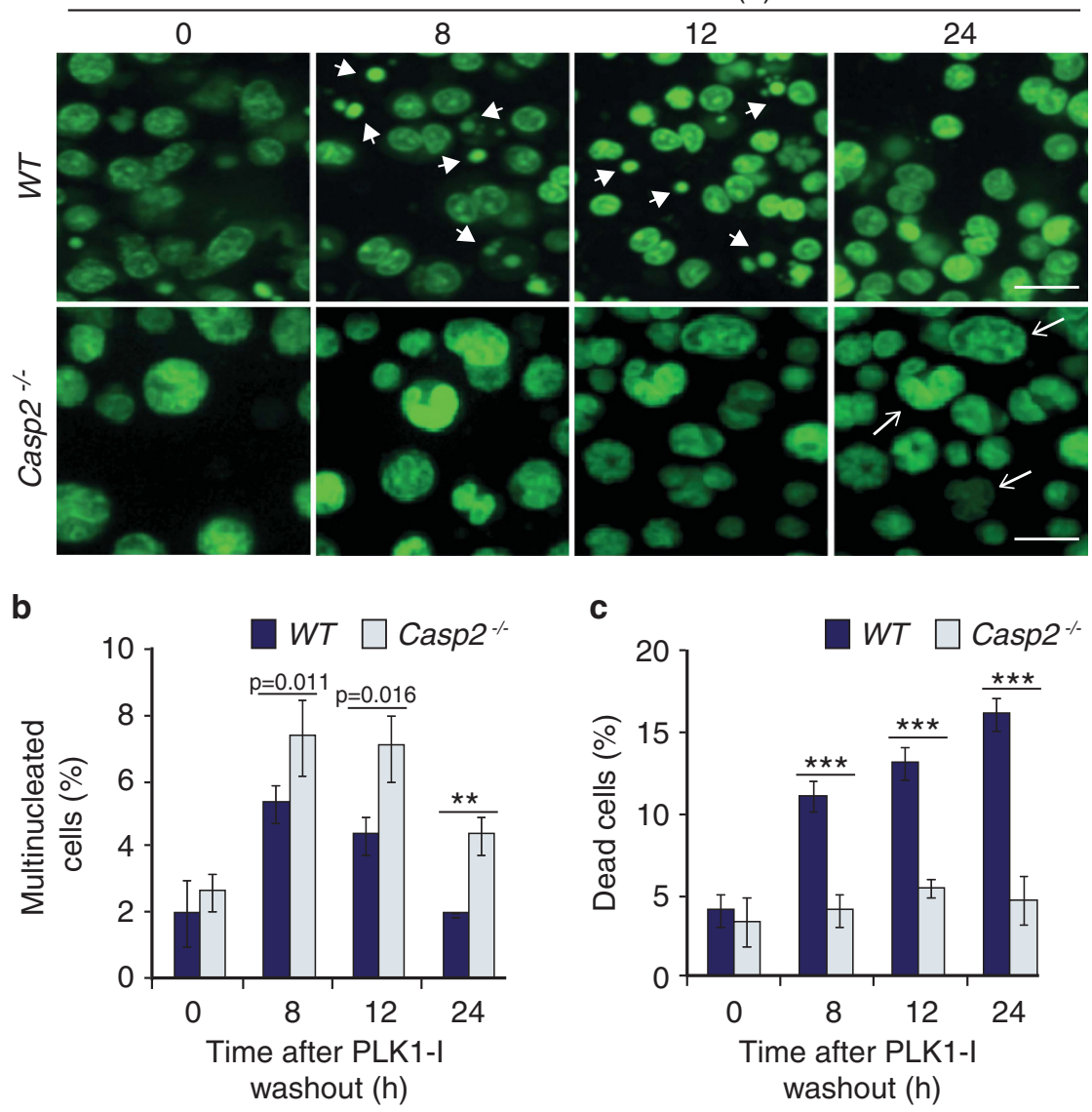

Figure 2. Loss of Caspase-2 leads to accumulation of multinucleated cells and reduced cell death in primary splenocytes following PLK1-I treatment. (a) Representative images from live cell imaging of WT and Casp $2^{-1-}$ splenocytes stained with Acriflavine, showing cells with multiple nuclei (arrows) and dead cells (arrow heads) at indicated time points following PLK1-I treatment. Scale bar $=50 \mu \mathrm{m}$. (b, c) Quantitation of (b) multinucleated cells and (c) and dead cells from WT and Casp2 ${ }^{-/-}$splenocytes at the indicated time points following PLK1-I treatment. Data represented as mean \pm s.d. from three independent experiments. $P$ values are indicated with ${ }^{* *} P<0.01,{ }^{* * *} P<0.001$ 
following CASP2-depletion, cells failed to enter metaphase but nuclei nevertheless underwent division to give rise to live multinucleated cells, whereas many of the control siRNA treated cells eventually entered metaphase and died soon after (Figure 3e and Movies 5-8). Imaging of the fate of single cells demonstrate control siRNA treated cells dying following PLK1-I treatment over a

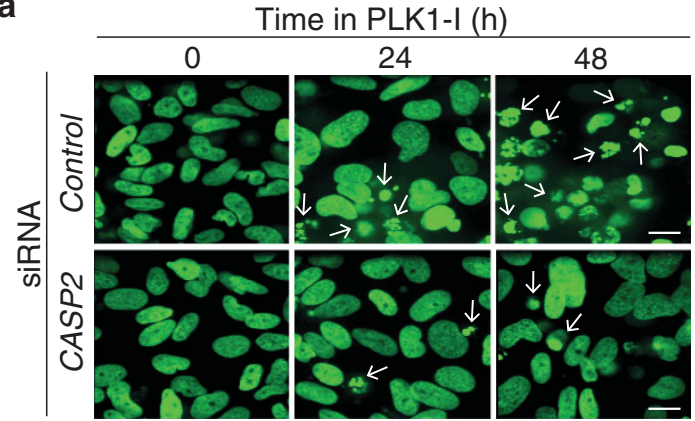

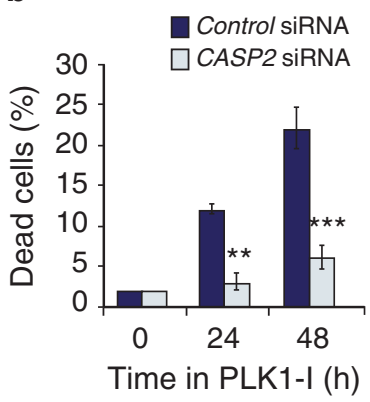

C Time after PLK1-I washout (h)

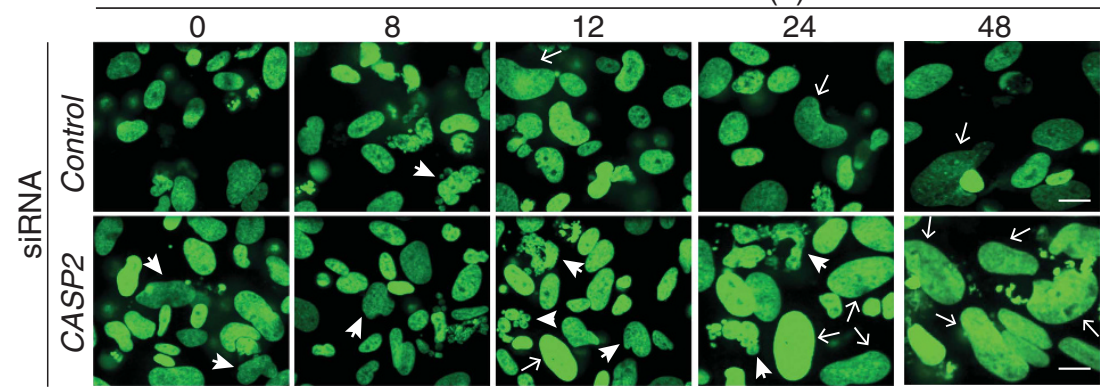

d

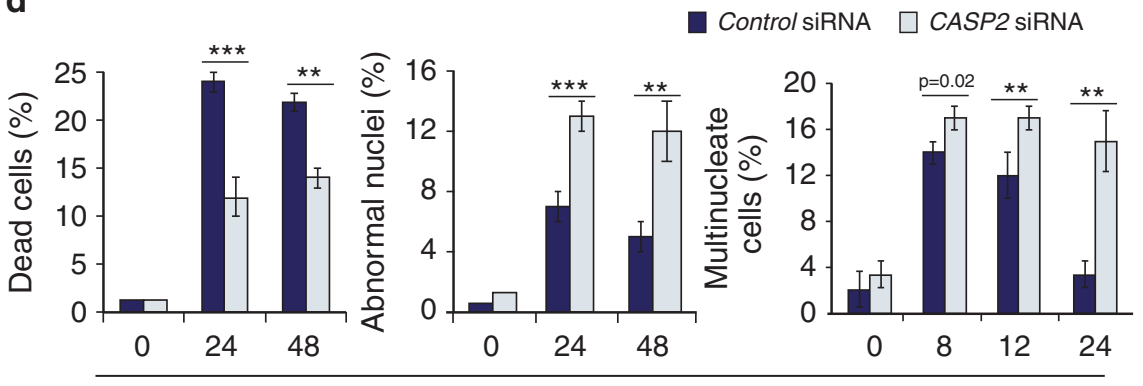

Time after PLK1-I washout (h)
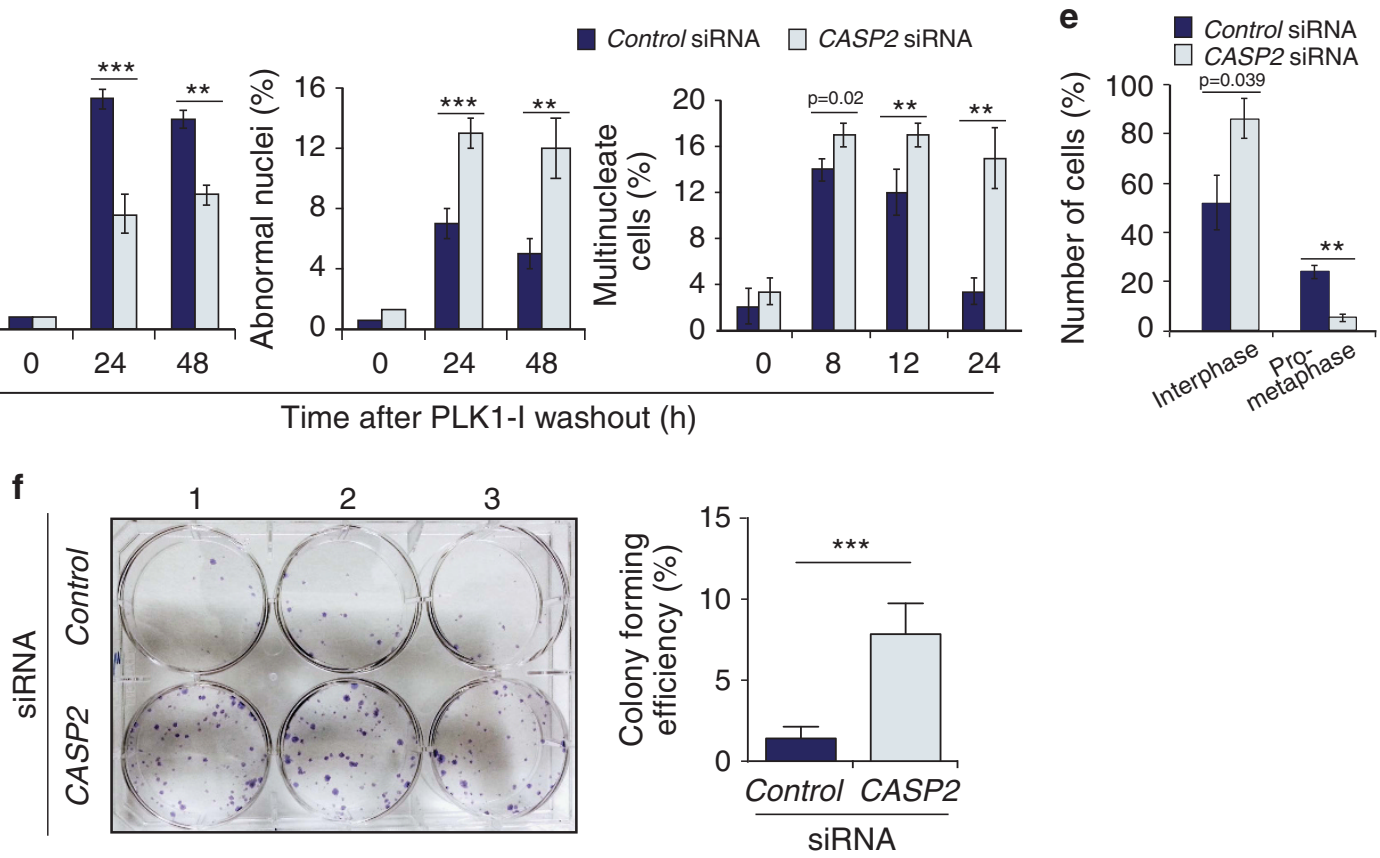

Figure 3. Acute knockdown of CASP2 affects cell death and promotes accumulation of cells with multiple and abnormal nuclei following PLK1I addition. (a) Representative images from live cell imaging of GFP-tagged histone H2B expressing U2OS cells treated with Control siRNA or CASP2 siRNA together with PLK1-I at the indicated time points, displaying dead cells (arrows). Scale bar $=50 \mu \mathrm{m}$. (b) Quantitation of dead cells in U2OS Control siRNA or CASP2 siRNA at indicated time points. Data represented as mean \pm s.d. from three independent experiments. $P$ values are indicated with ${ }^{* *} P<0.01,{ }^{* * *} P<0.001$. (c) Representative images from live cell imaging of H2B-GFP U2OS cells treated with Control siRNA or CASP2 siRNA at the indicated time points following PLK1-I washout, displaying multinucleated cells (arrows) and cells with abnormally large nuclei (arrow heads). Scale bar $=50 \mu \mathrm{m}$. (d) Quantitation of dead cells, multinucleated cells and cells with abnormal nuclei at indicated time points following PLK1-I washout. Data represented as mean \pm s.d. from three independent experiments. $P$ values are indicated with ${ }^{* *} P<0.01{ }^{* * *} P<0.001$. (e) Quantitation of cell cycle events following PLK1-I induced mitotic arrest. Data represented as mean \pm s.d. from three independent experiments. $P$ values are indicated with ${ }^{* *} P<0.01$. (f) Clonogenic assay. Representative image of crystal violet stained colonies in Control or CASP2 siRNA-transfected U2OS cells treated with PLK1-I (100 nM) for $48 \mathrm{~h}$ and cultured over 11 days. Experiment was carried out in triplicate and the colony was defined to consist of at least 50 cells. Quantitation of colony forming efficiency from three independent experiments is shown. Data represent mean \pm s.e.m. ${ }^{* * *} P<0.001$. 

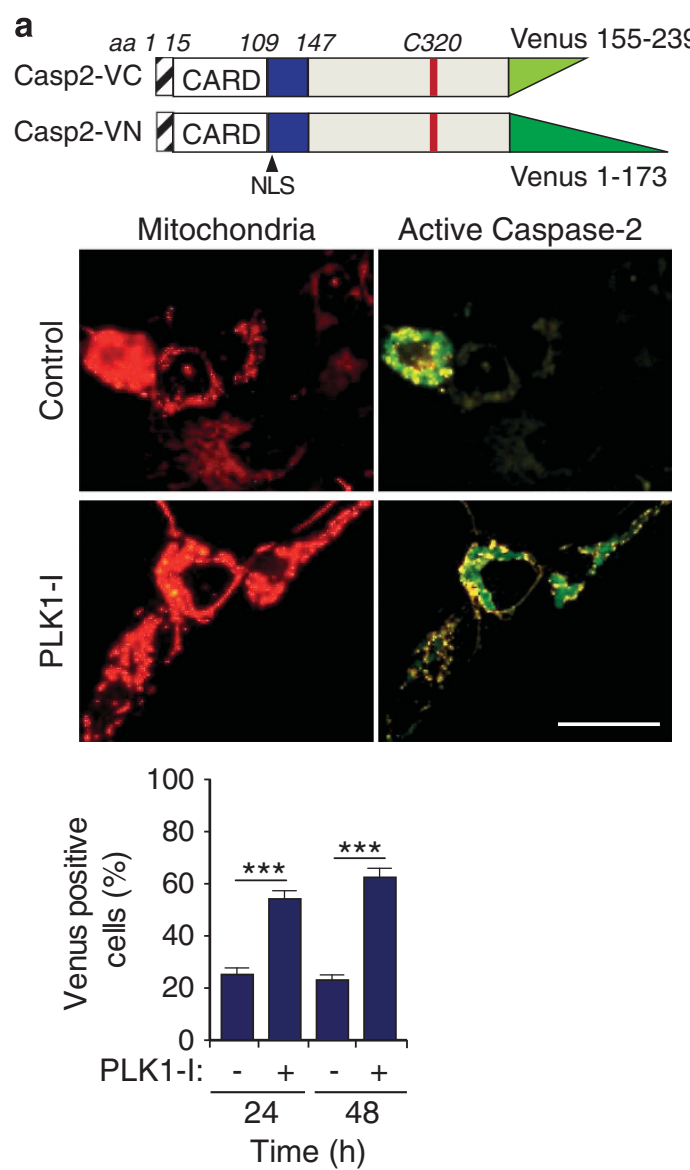

b

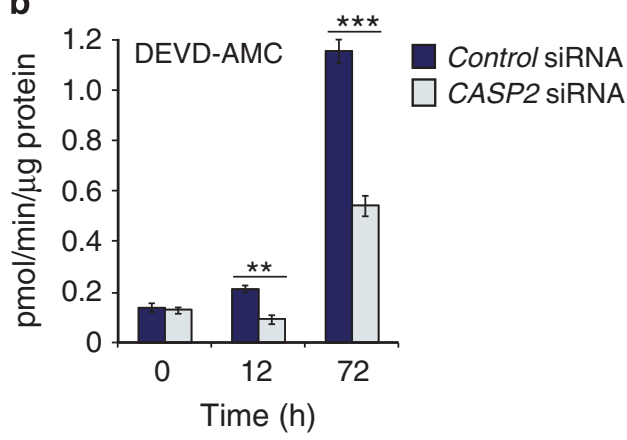

C

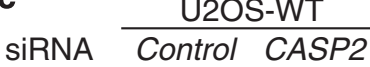

Time (h) $0 2 4 4 8 \longdiv { 0 2 4 4 8 }$

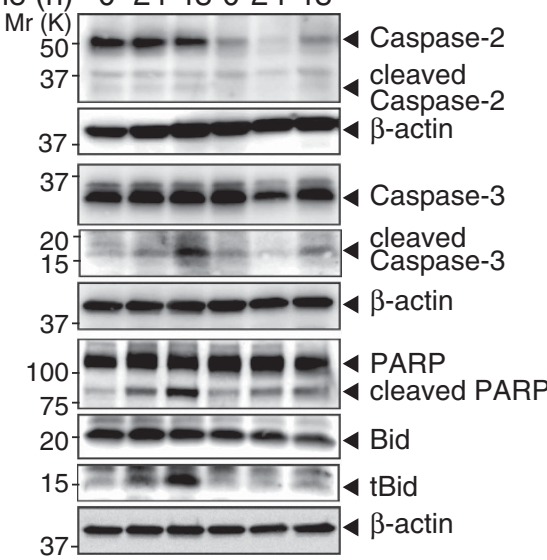

Figure 4. Caspase-2 activation in U2OS cells during mitotic arrest is required for apoptosis. (a) Caspase-2 Venus-tagged constructs used for $\mathrm{BiFC}$ assay and representative images showing caspase-2 activation at $24 \mathrm{~h}$ following PLK1-I treatment of U2OS cells. Scale bar $=20 \mu \mathrm{m}$. Quantitation of BiFC fluorescence is indicated. ${ }^{* * *} P<0.001$. (b) Caspase activity assays in U2OS cells treated with control or CASP2 siRNA over the indicated time points following PLK1-I, assessed by cleavage of DEVD-AMC. Data represented as mean \pm s.d. from three independent experiments. ${ }^{* *} P<0.01,{ }^{* *} P<0.001$. (c) Immunoblot analysis of caspase-2, caspase-3, PARP and Bid cleavage in U2OS cells treated with control or CASP2 siRNA over the indicated time points following PLK1-I.

$24 \mathrm{~h}$ and following washout (Supplementary Figure S5a and b). We did not observe any differences in the frequency of anaphase bridge formation but demonstrate CASP2 siRNA treated cells attempt (but fail) to undergo anaphase and are still able to survive over $48 \mathrm{~h}$ post PLK1-I washout (Supplementary Figure S5b). Together these findings suggest that CASP2 depletion can contribute to an increased incidence of mitotic slippage and survival of aberrant cells following PLK1-I treatment. ${ }^{29}$

To examine the long-term effect of CASP2 silencing on the survival of PLK1-I treated multinucleated and/or aneuploid cells we carried out a clonogenic assay and demonstrated a greater than fivefold increase in colony formation in cells depleted of CASP2 (Figure 3f). These findings indicate that caspase-2 depletion can enhance the clonogenic survival of aneuploid cells. Together these experiments clearly demonstrate that both acute silencing or ablation of caspase-2 is sufficient for enhanced accumulation and survival of cells with defective mitoses following PLK1 inhibition, which would otherwise have been deleted by cell death.

Caspase-2 activation is required for apoptosis following mitotic arrest

To assess caspase-2 activation following PLK1-I treatment we used the bimolecular fluorescence complementation (BiFC) assay with full-length CASP2 gene $(C 320 A)^{30}$ and demonstrate caspase-2 dimerization and activation following PLK1-I addition (Figure 4a). Analysis of the kinetics of PLK1-I-mediated cell death and caspase activation also demonstrated significantly reduced caspase-3-like activity in CASP2 siRNA treated U2OS cells (Figure 4b). We also examined the cleavage dynamics of various apoptotic proteins in U2OS cells following acute silencing of CASP2, and found that CASP2 SiRNA treatment markedly reduced the cleavage of both caspase-3 and PARP following PLK1-I treatment (Figure 4c).

Several studies have shown that caspase- 2 activation can occur upstream of mitochondrial outer membrane permeabilization (MOMP). ${ }^{12,31-33}$ Once active, caspase-2 cleaves Bid and this truncated Bid (tBid) induces MOMP and apoptosis. ${ }^{16,34}$ An examination of Bid protein levels in U2OS cells following CASP2 siRNA treatment also displayed markedly reduced cleavage (Figure 4c). These results suggest that the increased aneuploidy associated with the loss of caspase- 2 is due to the loss of caspase activity, which is required for Bid-mediated apoptosis.

Primary cells from Caspase-2 catalytic mutant mouse show enhanced aneuploidy

The catalytic activity of caspase- 2 has been shown to be required to inhibit tumorigenesis and mutation of the catalytic Cysteine residue (C320) in the caspase- 2 results in the loss of its tumour suppressor function. ${ }^{35}$ As the tumour suppressor function of caspase- 2 could be due to its ability in deleting aneuploid cells we 
a

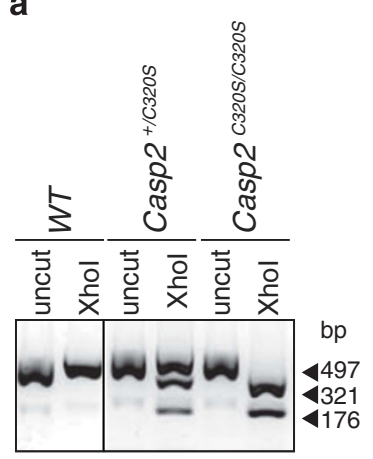

b

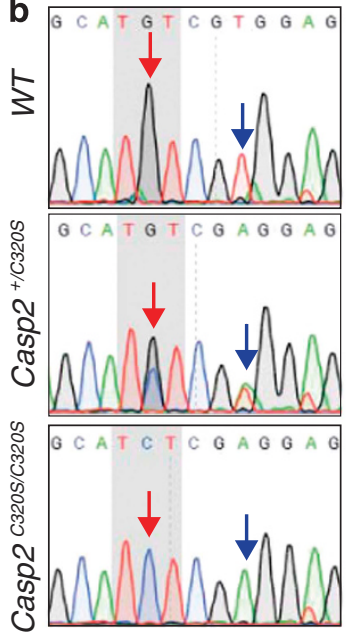

C

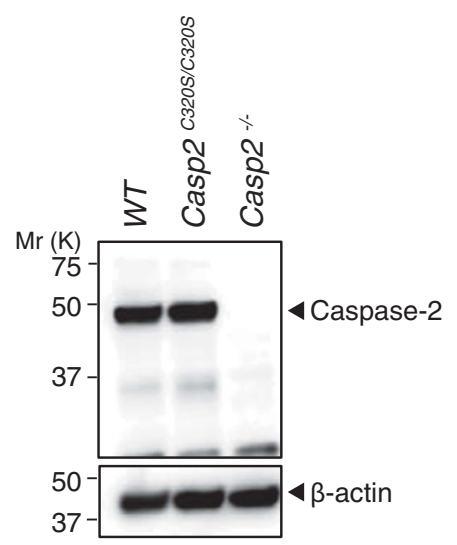

d

\begin{tabular}{|c|c|c|c|}
\hline Genotype & Observed (\%) & Expected (\%) & $P$ value \\
\hline Cross: $\operatorname{Casp}^{+/ C 320 S} \times \operatorname{Casp}^{+/ C 320 S}(\mathrm{n}=153)$ & & & \multirow{4}{*}{0.6349} \\
\hline Casp2 $^{+/+}$ & $37(24.2)$ & $38.25(25.0)$ & \\
\hline Casp2 $^{+/ \text {Cз20S }}$ & $82(53.6)$ & $76.50(50.0)$ & \\
\hline Casp2 ${ }^{\text {C320s/C320s }}$ & $34(22.2)$ & $38.25(25.0)$ & \\
\hline
\end{tabular}

Figure 5. Generation and validation of a Casp2 ${ }^{C 320 S}$ mice. (a) A representative DNA agarose gel image from genotyping of WT, Casp2 ${ }^{+/ C 320 S}$ (heterozygous) and Casp2 ${ }^{\mathrm{C} 320 S / \mathrm{C}^{2} 20 S}$ (homozygous) mice. The size of expected DNA fragments generated per genotype are indicated (bp). (b) DNA sequencing confirmation of the different genotypes as indicated. The red and blue arrows indicate the point mutation sites (G, $\mathrm{G} / \mathrm{C}$ or C) and the silent mutation site (T, T/A or A), respectively. (c) Immunoblot analysis of caspase-2 expression in splenocytes from WT and Casp2 $2^{C 320 S / C 320 S}$ mice. $\beta$-actin is shown as loading control. (d) Genotype frequencies of the progeny from Casp2 $2^{+/ C 320 S}$ (heterozygous) intercrossing including observed and expected numbers of offspring. Observed and expected frequency (\%) is indicated in parentheses. Statistical comparison was performed by $x^{2}$ test.

next examined the requirement of caspase- 2 catalytic activity in limiting aneuploidy and survival of multinucleated cells. To do this we generated a C320 mutant mouse allele, Casp2 $2^{\text {C320S }}$ by CRISPR/ Cas9 (Figure 5). We introduced a single point mutation that generated an Xhol site to facilitate genotyping of Casp2 $2^{\text {C320S }}$ heterozygous (Casp2 ${ }^{+/ C 3205}$ ) and homozygous (Casp2 $2^{\text {C320S/C320S }}$ ) mice (Figure $5 \mathrm{a}$ ). DNA sequencing confirmed the introduction of a $\mathrm{G}$ to $\mathrm{C}$ point mutation resulting in a C320S amino acid substitution (Figure $5 \mathrm{~b}$ ). Immunoblot analysis of caspase-2 protein expression in primary splenocytes confirmed expression levels of Caspase-2 mutant protein were comparable to WT (Figure $5 \mathrm{c}$ ). We have generated and maintained a colony of Casp2 ${ }^{\mathrm{C} 320 \mathrm{~S}}$ mice by intercrossing Casp2 ${ }^{+/ C 3205}$ mice over 6 months. Consistent with

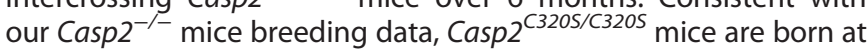
normal mendelian frequency (Figure $5 \mathrm{~d}$ ) with males and females produced at normal 1:1 ratio. Observation of these mice over a 6-month period has not detected any overt phenotypic differences compared to WT animals.

We next examined PLK1-I induced aneuploidy and cell death in

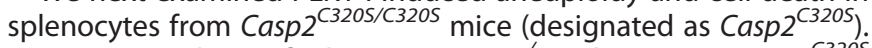
Consistent with our findings in Casp2 $2^{-1-}$ splenocytes, Casp2 ${ }^{\mathrm{C} 320 \mathrm{~S}}$ splenocytes showed significantly greater level of aneuploidy (Figure 6a) and increased resistance to cell death (Figure 6b) following PLK1-I treatment. In addition, live cell imaging of Casp2 $2^{\text {C320S }}$ splenocytes demonstrated increased numbers of surviving multinucleate cells and reduced number of dying/dead cells (Figures $6 \mathrm{c}-\mathrm{e}$ ). These are the first findings detailing the requirement of caspase-2 catalytic activity in limiting aneuploidy. Importantly they conclusively demonstrate a critical role of caspase-2 function in apoptosis of multinucleated and/or aneuploid cells following mitotic stress.

\section{DISCUSSION}

This study demonstrates an important requirement for caspase-2 enzymatic activity in the apoptotic removal of mitotically aberrant cells in response to replicative stress. We describe the generation of Casp2 $2^{\mathrm{C} 320 \mathrm{~S}}$ mutant mice and provide the first demonstration that caspase- 2 catalytic mutation increases susceptibility to aneuploidy. These data are consistent with an in vitro study showing a potential function for caspase- 2 in mitotic catastrophe. ${ }^{5}$ Our data further demonstrate that loss of caspase-2 promotes the long-term survival of mitotically aberrant cells that could potentially become tumorigenic.

Our imaging data suggest that caspase- 2 activation occurs when a specific mitotic checkpoint is breached. Interestingly, closer analyses of real time movies show that in contrast to WT cells, many PLK-1 inhibited Casp2 ${ }^{-/-}$cells appear to exit mitosis in prometaphase without entering metaphase. Instead, cells enter an interphase-like state as multinucleated and/or aneuploid cells, with enhanced ability to survive. Our findings indicate that loss of caspase-2 affects mitosis during the prometaphase to metaphase transition, which may include spindle assembly or chromosome alignment to spindle. In previous analyses using MEFs we did not detect abnormalities in spindle formation or formation of anaphase bridges in Casp2 $2^{-/-}$ cells during mitosis and following mitotic arrest. ${ }^{13}$ Further defining the exact mitotic checkpoint and requirement for caspase-2 would be important in future studies.

Several studies have previously implicated caspase- 2 in cell cycle regulation and mitotic cell death. ${ }^{5,16,36-38}$ Activation of the SAC by disrupting microtubule stability has been shown to require caspase-2 for induction of cell death. ${ }^{16}$ Caspase- 2 has also been 

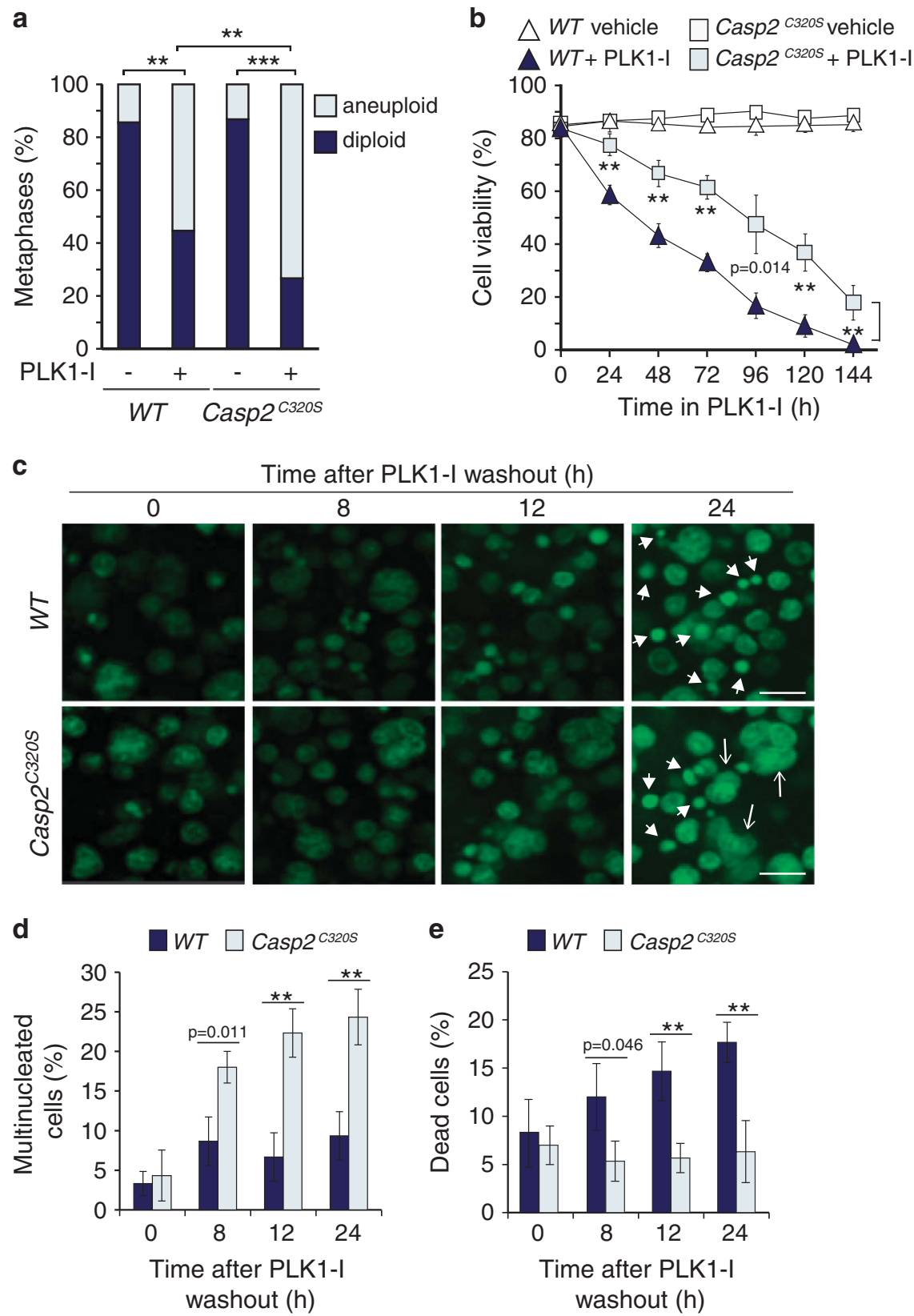

Figure 6. Caspase-2 catalytic cysteine mutant enhances aneuploidy. (a) Quantitation of metaphases showing frequencies of diploid and aneuploid karyotypes in untreated and PLK1 inhibitor (PLK1-I) treated WT $(n=3)$ and Casp2 ${ }^{\text {C320S/C320S }}$ (designated as Casp2 ${ }^{C 3205}$ ) ( $n=3$ ) splenocytes. A total of 50 metaphase spreads were counted per mouse. $P$ values are indicated with ${ }^{* * P}<0.01, * * * P<0.001, X^{2}$ test. (b) Quantitation of viable cells in WT and Casp2 ${ }^{C 320 S}$ splenocytes treated with PLK1-I for the indicated time points, determined by trypan blue assay. Data represented as mean \pm s.e.m. from three independent experiments. $P$ values are indicated with ${ }^{* *} P<0.01$. (c) Representative images from live cell imaging of WT and Casp2 ${ }^{\mathrm{C} 320 S}$ splenocytes stained with Acriflavine, showing cells with multiple nuclei (arrows) and dead cells (arrow heads) at the indicated time points following PLK1-I treatment. Scale bar $=50 \mu \mathrm{m}$. (d, e) Quantitation of multi nucleated cells (d) and dead cells (e) at the indicated time points, following PLK1-I washout. Data represented as mean \pm s.d. from three independent experiments. $P$ values are indicated with ${ }^{* *} P<0.01,{ }^{* * *} P<0.001$

implicated in mitotic catastrophe, via MOMP-dependent and p53-independent apoptosis. ${ }^{5,7}$ Our cell death data in conjunction with our live cell imaging results demonstrate that cells treated with PLK1-I underwent a mitotic arrest that eventually led to mitotic death, consistent with the published definition of mitotic catastrophe. ${ }^{6,39,40}$ Cleavage of caspase-2, caspase-3 and PARP following PLK1-I confirmed cells are undergoing apoptosis.

Silencing of caspase-2 has previously been shown to promote cell cycle progression and mitotic slippage, resulting in asymmetric cell division and aneuploidy. ${ }^{7}$ Our own studies have demonstrated loss of caspase-2 enhances DNA damage, micronuclei and aneuploidy in cultured cells and in tumours. ${ }^{13}$ The increased frequency of micronuclei formation is associated with lagging chromosomes, a likely cause of aneuploidy in these cells. Causes of lagging chromosomes include unresolved merotelic attachment of the kinetochore and microtubules and/or cytokinesis failure. Aberrant merotelic attachments can still satisfy the SAC, so that anaphase can take place despite their presence. ${ }^{41,42}$ Merotelic attachments are often detected in cells that carry abnormal centrosome number and it is important to note that 
supernumerical centrosomes can arise from cytokinesis failure. It is not yet known whether cells deficient for caspase- 2 have aberrant centrosome number or exhibit aberrant cytokinesis, features that may explain the occurrence of lagging chromosomes and enhanced aneuploidy.

A defective SAC pathway can induce premature anaphase, lagging chromosomes and micronucleus formation without detectable mitotic arrest. ${ }^{43,44}$ It is plausible that in addition to a role in cell death, caspase- 2 has an additional role in SAC regulation. However, many observations from Casp2-deficient mice are consistent with caspase- 2 playing a role in removing aberrant cells by apoptosis. Although Casp2-deficient mice do not spontaneously develop tumours, caspase-2 loss results in animals that are sensitized to stress, as apparent from a mild premature ageing phenotype. ${ }^{45,46}$ Increased oxidative stress and more damaged cells in the liver of aged $\mathrm{Casp}^{-/-}$mice, and the increased genomic instability seen in tumours from $E \mu M y c ; C a s p 2^{-1-}$, $\mathrm{Atm}^{-1-} ; \mathrm{Casp2}^{-1-}$; and MMTV/c-neu; Casp2 ${ }^{-1-}$ mice, are all consistent with a role of caspase-2 in deleting aneuploid cells by apoptosis. Our findings that $\mathrm{Atm}^{-/-} ; \mathrm{Casp}^{-1-}$ lymphoma cells are more resistant to PLK1-I-mediated cell death may have important implications for drug resistance in lymphoma treatment. ${ }^{47}$ It is important to note that, while in most dividing cells caspase- 2 is inactive, ${ }^{36}$ our findings demonstrate that following mitotic stress, a small population of Casp2 $2^{-/-}$cells are resistant to apoptosis and survive as multinucleate and aneuploid cells. Importantly, these cells acquire an ability to survive long term in culture, an attribute likely to contribute to enhanced cellular transformation and tumorigenic potential.

Moreover, caspase-2 phosphorylation at Ser340 by the mitosis-promoting kinase, cdk1-cyclin B1, maintains it in an inactive state during mitosis and activation of caspase-2 can lead to mitotic catastrophe. ${ }^{36}$ Consistent with these findings, our study now shows that catalytic inactivation of caspase- 2 prevents mitotic cell death. Importantly, our data demonstrate that caspase-2 inactivation or deficiency directly enhances aneuploidy. Furthermore, caspase-2 silencing enhances clonogenic survival of multinucleated and aneuploidy cells, suggesting a mechanism by which loss of caspase-2 can enhance susceptibility to tumorigenic transformation and underpins the mechanism by which caspase-2 acts as a tumour suppressor.

While other caspases, such as caspase- 3 and caspase-9, have been shown to play a role in deleting cells with damaged DNA, micronuclei or polyploidy, ${ }^{48,49}$ our studies indicate that caspase-2 plays a dominant role in deletion of mitotically aberrant cells in our system, since caspase- 2 deficiency promotes aneuploidy to a similar extent as does zVAD-mediated inhibition of caspases in WT cells. We show that caspase-2 can limit aneuploidy via Bidmediated apoptosis, which further support previous findings that caspase- 2 functions upstream of MOMP, caspase- 9 and caspase- 3 activation. ${ }^{5}$ In addition, we know from mouse models that this function is independent of caspase- 2 interacting proteins RAIDD and PIDD, as loss of these genes does not promote increased aneuploidy in cells in culture or in tumours. ${ }^{17}$ Interestingly, previous studies have shown that Bid does not appear to be essential for DNA damage or replicative stress-induced apoptosis or cell-cycle arrest. ${ }^{50}$ Therefore it is possible that caspase- 2 may also be able to promote apoptosis of mitotically aberrant cells in a Bid-independent manner.

This study has established a connection between caspase-2 deficiency and a multi nucleated and aneuploid phenotype by attenuation of apoptosis. This multinucleation and aneuploid phenotype in Casp2 ${ }^{-/-}$cells appears to be specific in response disruption of the spindle assembly during mitosis. We propose that, along with the conventional intrinsic apoptosis pathway, caspase-2-dependent cell death augments efficient removal of cells with chromosomal defects to limit aneuploidy in vivo. Additional studies are required to determine the factors required for survival and proliferation of Casp2 $2^{-/-}$aneuploid cells, and whether these cells have enhanced tumorigenic ability and drugresistance. Such knowledge will be essential for understanding and defining future chemotherapeutic strategies in drug-resistant cancers.

\section{MATERIALS AND METHODS}

Mice

Casp $^{-1-}$ mice ${ }^{14,51}$ have been described previously. Animals were maintained in specific pathogen-free conditions at the SA Pathology Animal care facility and all animal breeding and studies were approved by the SA Pathology/Central Northern Adelaide Health Services Animal Ethics Committee. An equal number (between 3 and 5) of healthy adult mice (6-8 weeks) of each genotype were randomly euthanized for primary cell collection for each experiment. Selection of mice per genotype was not blinded.

\section{Generation of Casp2 ${ }^{\mathrm{C} 320 \mathrm{~S}}$ mutant mice}

CRISPR/Cas9 technology was used to generate Casp2 ${ }^{\text {C320S }}$ mutant mice by SA Genome Editing Facility (Adelaide, Australia). Guide oligonucleotides (Geneworks, Thebarton, SA, Australia) were denatured at $95^{\circ} \mathrm{C}$ for $5 \mathrm{~min}$ and annealed at $25^{\circ} \mathrm{C}$ before being ligated into Bbsl linearized px330 vector (Addgene, Cambridge, MA, USA). A template for in vitro transcription was generated by PCR amplification of the pX330 vector using a forward primer containing a 5' T7 promoter sequence and a reverse primer that bound the TracR sequence. In vitro transcription was performed using the HiScribe T7 In Vitro Transcription Kit (NEB, Ipswich, MA, USA) and transcribed gRNA was purified using RNeasy Mini Kit (QIAGEN, Hilden, Germany). The donor oligonucleotide (Integrated DNA Technologies, Coralville, IA, USA) contained the intended point mutation as well as a silent mutation that introduced a Xhol restriction site that was used to screen mutant alleles. To produce Cas 9 mRNA, Cas 9 plasmid was linearized using Xhol restriction enzyme (NEB) and mRNA was transcribed using mMessage mMachine T7 Ultra Kit (Life technologies, Carlsbad, CA, USA) followed by capping and polyadenylation. C57BL/6 females were superovulated by injecting 5IU PMSG (Folligon; Intervet India, Pune, Maharashtra, India) followed by 5IU hCG (Chorulon; Intervet India) $47.5 \mathrm{~h}$ later. Superovulated females were mated to male C57BL/6 mice and fertilized oocytes were collected from oviducts in a Hepes buffered flushing and holding medium (FHM) (Merck Millipore, Darmstadt, Germany). Oocytes were maintained in $\mathrm{KSOM}^{\mathrm{AA}}$ (Merck Millipore) at $37{ }^{\circ} \mathrm{C}$ in $5 \% \mathrm{CO}_{2}$ and were screened for the presence of two pronuclei to indicate fertilization. Fertilized oocytes were microinjected with a buffered solution containing Cas9 mRNA (100 ng/ $\mu \mathrm{l})$, sgRNA $(50 \mathrm{ng} / \mu \mathrm{l})$ and donor oligo $(100 \mathrm{ng} / \mu \mathrm{L})$ in FHM before being transferred to the oviduct of a psuedopregnant Swiss female mouse. For genotyping of mutant mice including founder mice, genomic DNA was extracted from postnatal day 10 tail tissue using High Pure PCR Template Preparation Kit (ROCHE, Basel Schweiz, Switzerland). A $497 \mathrm{bp}$ fragment containing the putative mutation was amplified by PCR and digested with Xhol restriction enzyme. Mutant alleles showed digested products of 321 and $176 \mathrm{bp}$.

The following oligonucleotides were used for the generation of Casp2 ${ }^{\mathrm{C} 320 \mathrm{~S}}$ mice:

Donor Oligo:

5'TTGACAATGCTAACTGTCCAAGTCTACAGAACAAGCCAAAAATGTTCTTCA TCCAAGCATCTCGAGGAGGTGAGTGCCCTGGCAAACCAGCACCTGGGTGGTG GCTCCTGGGCAGCCTCCACCAG-3'

(C; point mutation target; A, silent mutation for Xhol site introduction). Forward Guide Oligo: 5'-CACCGTTCATCCAAGCATGTCGTGG-3

Reverse Guide Oligo: 5'-AAACCCACGACATGCTTGGATGAAC-3'

T7 PCR Oligo: 5'-TTAATACGACTCACTATAGTTCATCCAAGCATGTCGTGG-3'

The following oligonucleotides were designed for genotyping Casp2 ${ }^{\mathrm{C3} 20 \mathrm{~S}}$ mice:

F-mC2-C320S: 5'-TTTGCCCCAACCCTTTCAGT-3'; R-mC2-C320S: 5'-CCCA TGCATTGGGAGACACT-3'.

\section{Cell culture}

Primary cells were collected from at least three independent mice per genotype (sample size is indicated in figure legends) and the analysis of primary cells was performed in randomized and blinded manner. Primary splenocytes were extracted from 6-8-week-old WT, Casp2 ${ }^{-1-}$ and Casp2 ${ }^{\text {C32O }}$ 
mice. Briefly, spleens were homogenized and cells filtered through $40 \mu \mathrm{m}$ nylon mesh filter and incubated in red blood cell lysis buffer (155 mM $\mathrm{NH}_{4} \mathrm{Cl}, 10 \mathrm{~mm} \mathrm{NaHCO}$ ) for $5 \mathrm{~min}$ at room temperature. Cells were stimulated with $10 \mu \mathrm{g} / \mathrm{ml}$ concanavalin A (ConA) (Sigma-Aldrich, St Louis, $\mathrm{MO}, \mathrm{USA}$ ) for the first $48 \mathrm{~h}$ followed by culturing in $100 \mathrm{U} / \mathrm{ml}$ recombinant mouse $\mathrm{IL}-2$, at $37{ }^{\circ} \mathrm{C}$ with $5 \% \mathrm{CO}_{2}$ in DMEM media (Sigma-Aldrich) supplemented with $10 \%$ fetal bovine serum (JRH Biosciences, Lenexa, KS, USA), $50 \mu \mathrm{m} \beta$-mercaptoethanol (Amersham, GE Healthcare Life Sciences, Little Chalfont, UK), non-essential amino acid mix (Sigma-Aldrich), $0.2 \mathrm{~mm} \mathrm{I-}$ glutamine (Sigma-Aldrich), $15 \mathrm{~mm}$ HEPES (Sigma-Aldrich) and $100 \mu \mathrm{m}$ penicillin/streptomycin (Sigma-Aldrich). The human osteosarcoma (U2OS) cell line (obtained from ATCC) were maintained at $10 \% \mathrm{CO}_{2}$ in DMEM media (Sigma-Aldrich) supplemented with $10 \%$ fetal bovine serum (JRH Biosciences), $0.2 \mathrm{~mm} \mathrm{l-glutamine} \mathrm{(Sigma-Aldrich),} 15 \mathrm{~mm}$ HEPES (Sigma-Aldrich) and $100 \mu \mathrm{m}$ penicillin/streptomycin (Sigma-Aldrich). Where indicated, cells were treated with the PLK-1 inhibitor BI 2536 (50 nm) (Axom medchem, Hanzeplein, Groningen, Netherlands), over $48 \mathrm{~h}$, Paclitaxel (100 nм) (Sigma-Aldrich) or the Eg5 inhibitor monastrol (5 $\mu \mathrm{m})$ (Sigma-Aldrich) over $72 \mathrm{~h}$. Cell synchronization was carried out using either a single-thymidine (for BiFC) or double-thymidine (for immunoblotting) block ( $2 \mathrm{~mm}$ ) prior to treatment with BI 2536 (100 nM). Cell viability was determined by trypan blue dye exclusion. For population doubling times, primary splenocytes were seeded at $1 \times 10^{6}$ in six-well plates at day 0 . Cells were harvested on day 6 and 8 following Con-A stimulation and number of viable cells were estimated by trypan blue exclusion. The doubling time was calculated as: $t / n$; where $t=$ number of days for $n$ population doublings to occur and $n=$ number of population doublings and was calculated as $n=\log (B / A) / \log 2 ;$ where $A=$ initial cell number; $B=$ final cell number. Healthy, exponentially growing cells were used in all experiments.

Live cell imaging

Freshly isolated splenocytes were imaged in $35 \mathrm{~mm}$ imaging dishes ( $\mu$-Dish $35 \mathrm{~mm}$, low; Ibidi, Martinsried, Germany) coated with $0.01 \%$ poly-Ilysine (Sigma-Aldrich). Cells were either untreated or treated with BI 2536 (24 h after drug washout) and stained with $1 \mu \mathrm{m}$ Acriflavine dye (SigmaAldrich) prior to imaging. U2OS cells stably expressing GFP-tagged histone $\mathrm{H} 2 \mathrm{~B}$ were generated using the $\mathrm{pBOS}-\mathrm{H} 2 \mathrm{BGFP}$ vector $(\mathrm{BD}$, Biosciences, San Jose, CA, USA) and were grown in $\mu$-slide eight-well chambered dishes (Ibidi). U2OS cells were transfected with control or CASP2 siRNA (as described below) prior to treatment with $\mathrm{BI} 2536$ and imaged for $48 \mathrm{~h}$. Following washout of BI 2536, cells were imaged for a further $48 \mathrm{~h}$. Frames were captured at 3 min intervals. All live cell imaging was repeated with at least three independent batches of cells, and the average number of multinucleate, 'giant' and dead cells per high-power field was calculated and statistically analysed. Live cell imaging was carried out in Cell Voyager CV1000 Confocal Scanner (Yokogawa Electric Corporation, Tokyo, Japan). Images were trimmed using QuickTime Player.

\section{Knockdown of caspase-2 expression by siRNA}

Caspase-2 knockdown by siRNA has been previously described. ${ }^{45}$ Two different sets of siRNA (purchased from GenePharma, Shanghai, China) were used to minimize any potential off-target effects, with the following sequences; CASP2 siRNA-1 (5'-ACAGCUGUUGUUGAGCGAAdTdT-3'), CASP2 SIRNA-2 (5'-GUUGUUGAGCGAAUUGUUATT-3'), control siRNA (5'-UAAGGC UAUGAAGAGAUACTT-3'). All transfections were carried out using Trans IT-TKO transfection reagent (Mirus, Madison, WI, USA) for $48 \mathrm{~h}$ according to manufacturer's instructions. Briefly, U2OS cells $\left(1 \times 10^{5}\right)$ were seeded into $60 \mathrm{~mm}$ dishes in $2 \mathrm{ml}$ complete medium and allowed to adhere for 16-24 h. $2.5 \mu \mathrm{l}(20 \mu \mathrm{m}$ siRNA) and $3 \mu \mathrm{l}$ of TransIT-TKO siRNA transfection reagent (Mirus) were diluted to $100 \mu \mathrm{l}$ in Opti-MEM (Sigma-Aldrich) and incubated for $15 \mathrm{~min}$ at room temperature. The diluted siRNA and transfection reagent were combined and incubated for a further $15 \mathrm{~min}$ at room temperature and then overlaid onto cells. After $30 \mathrm{~h}$ incubation at $37^{\circ} \mathrm{C}$ in the transfection complexes, the media was replaced and cells were allowed to recover for $12 \mathrm{~h}$ before treatment with BI 2536 (100 nм) for $48 \mathrm{~h}$ and harvesting for protein analysis. Knockdown experiments were repeated at least three times and the results statistically analysed.

\section{Cytogenetic analysis}

Preparation of chromosome spreads from untreated and BI 2536-treated splenocytes was carried out as previously described ${ }^{13}$ by adding colcemid $(20 \mathrm{ng} / \mathrm{ml}), 4 \mathrm{~h}$ prior to harvesting cells by trypsinization, hypotonic treatment $(0.075 \mathrm{M} \mathrm{KCl})$ and fixation in fresh ice cold Carnoy's fixative (methanol:glacial acetic acid at 3:1) for $10 \mathrm{~min}$ at $37^{\circ} \mathrm{C}$. Cells were centrifuged at $1000 \mathrm{rpm}$, washed three times in Carnoy's fixative and dropped onto wet glass slides, air dried and then placed in a $60^{\circ} \mathrm{C}$ oven overnight. Cells were stained with DAPI and chromosomes quantitated by epifluorescence microscopy (model BX51; Olympus, Tokyo, Japan) and camera (UCMAD3/CVM300, Olympus). Cells were visualized under $\times 40$ or $\times 100$ ULAPO objective lens with NA $=1.5$. Images were processed using Olysia BioReport Software (Olympus) and manually merged using Adobe Photoshop 6.0 software. Cytogenetic analysis was repeated with at least three different batches of cells, and the average number of chromosomes per cell per high-power field was calculated and statistically analysed. Chromosomal counts were carried out in a randomized and blinded manner.

\section{Caspase activation assays}

Caspase substrate activity assays using DEVD-AMC were carried out as previously described ${ }^{52}$ BiFC analysis for caspase-2 activation was performed as described previously with minor modification. ${ }^{53}$ Briefly, full-length caspase-2 protein was fused to fragments of Venus (super enhanced YFP) constructs to yield CASP2 $\mathrm{FL}_{\mathrm{FL}}-\mathrm{VN}$ (Venus fragment 1-173) and CASP2 ${ }_{\mathrm{FL}}-\mathrm{VC}$ (Venus fragment 155-239). $2 \times 10^{4}$ U2OS cells in complete culture medium were seeded onto $13 \mathrm{~mm}$ glass coverslips (Thermo Fisher Scientific, Waltham, MA, USA) in a 24-well plate and incubated overnight at $37^{\circ} \mathrm{C}$ in a $10 \% \mathrm{CO}_{2}$ incubator. The next day cells were co-transfected with $150 \mathrm{ng}$ of the pBiFC-HA-Capase-2 FL (C320A)-VC155 and pBiFC-HACaspase-2 FL (C320A)-VN173 for BiFC and 10 ng of pDsRed-Mito (Clontech, Mountain View, CA, USA) as a transfection reporter plasmid, using Fugene HD reagent (Promega, Madison, WI, USA) according to the manufacturer's instruction. After incubation for $5 \mathrm{~h}$, the medium was replaced with complete culture medium containing z-VAD-fmk $(20 \mu \mathrm{m})$ and cells were incubated a further $24 \mathrm{~h}$ at $37^{\circ} \mathrm{C}$ in a $10 \% \mathrm{CO}_{2}$ incubator. Cells were then synchronized with thymidine ( $2 \mathrm{~mm}$; Sigma-Aldrich) and incubated for $24 \mathrm{~h}$ at $37{ }^{\circ} \mathrm{C}$ in a $10 \% \mathrm{CO}_{2}$ incubator. Cells were washed with pre-warmed PBS and covered with complete culture medium containing DMSO (control) or z-VAD-fmk (20 $\mu \mathrm{m})$ with or without PLK1-I (BI 2536-100 nM). Cells were fixed at $24 \mathrm{~h}$ and $48 \mathrm{~h}$ after treatment. Caspase substrate activity experiments were repeated at least three times, and results statistically analysed. CX40 epifluorescence microscope (Olympus) was used for imaging BiFC and analysis. To quantify BiFC-positive cells, total 1065 ( $24 \mathrm{~h}$ control), 394 ( $24 \mathrm{~h}$ BI 2536), 926 ( $48 \mathrm{~h}$ control) and 391 ( $48 \mathrm{~h} \mathrm{BI} 2536$ ) cells were counted in three different areas in four independent experiments. Statistical analysis was carried out in GraphPad Prism, Version 6.05 (GraphPad, GraphPad Software Inc., La Jolla, CA, USA).

\section{Immunoblotting}

Protein lysates were prepared from primary splenocytes or tumour tissue by cell lysis and/or homogenization in RIPA buffer [ $25 \mathrm{~mm}$ Tris/ $/ \mathrm{HCl} \mathrm{pH} \mathrm{7.4,}$ $150 \mathrm{~mm} \mathrm{NaCl}, 1 \%$ nonyl-phenoxylpolyethoxylethanol (NP-40), 1\% sodium deoxycholate, $0.1 \%$ sodium dodecyl sulphate (SDS)], in the presence of protease/phosphatase inhibitor cocktail (Thermo Fisher Scientific). Homogenates were treated by three freeze/thaw cycles in liquid nitrogen, clarified by centrifugation at $13.2 \mathrm{~K} \mathrm{rpm}$ and protein concentration determined by BCA quantitation (Bio-Rad, Hercules, CA, USA). 30 or $50 \mu \mathrm{g}$ of lysates were resolved on 4-20\% Mini-PROTEAN TGX gel (Bio-Rad), 12 or $15 \%$ SDS-PAGE gel as appropriate and transferred onto PVDF membrane and probed for the specified antibody for $2 \mathrm{~h}$ at room temperature or overnight at $4{ }^{\circ} \mathrm{C}$. Secondary antibodies, conjugated with horseradish peroxidase, alkaline phosphatase or Cy5 (Millipore/GE Healthcare, Chicago, IL, USA), were incubated at room temperature for $2 \mathrm{~h}$. Proteins were visualized using ECF or ECL (Millipore/GE Healthcare). The following antibodies were used: caspase-2 (clone 11B4), PARP (\#9542), caspase-3 (\#9662), Mad2 (\#4636) (Cell Signalling Technology, Danvers, MA, USA), cyclin B1 (\#sc-245) (Santa Cruz Biotechnology, Santa Cruz, CA, USA), $\beta$-actin (\#A5316), Bub3 (\#B7811) (Sigma-Aldrich), Bid (\#AF846) (R\&D Systems, Minneapolis, MN, USA) and Cdc20 (\#ab183479) (Abcam, Cambridge, MA, USA). Immunoblotting experiments were repeated at least three times, and the results were statistically analysed.

\section{Clonogenic assays}

Clonogenic assays were carried out as previously described. ${ }^{54}$ Briefly, U2OS cells were seeded at $1 \times 10^{5}$ cells in a $60 \mathrm{~mm}$ dish. Cells were transfected with either control or CASP2 siRNA for $48 \mathrm{~h}$ followed by treatment with PLK1-I (100 nM) for a further $48 \mathrm{~h}$. Cells were then harvested and reseeded 
at a density of 800 viable cells per well in a six-well plate, in triplicate. After culturing 11 days, the colonies were stained with $6 \%$ glutaraldehyde (Ajax Finechem, NSW, Australia) and $0.5 \%$ crystal violet (Sigma-Aldrich) and counted using a stereomicroscope (Nikon, Tokyo, Japan). A colony was defined as consisting of at least 50 cells and experiments were repeated at least three times for statistical analysis. Colony forming efficiency $(\%)=($ total number of colonies/number plated cells) $100 \%$.

\section{Flow cytometry}

Splenocytes $\left(2 \times 10^{6}\right)$ either untreated or treated with BI $2536(50 \mathrm{~nm})$ were fixed in $70 \% \mathrm{v} / \mathrm{v}$ ethanol and stored at $-20^{\circ} \mathrm{C}$. Fixed cells were rehydrated by washing 2-3 times in PBS with centrifugation at $500 \times \mathrm{g}$ for $5 \mathrm{~min}$. Cells were then permeabilized with $0.25 \% \mathrm{v} / \mathrm{v}$ Triton X-100/PBS for $10 \mathrm{~min}$ at room temperature and then incubated in staining solution containing $40 \mu \mathrm{g} / \mathrm{mL}$ RNase A (Roche) and $25 \mu \mathrm{g} / \mathrm{ml}$ propidum iodide (Sigma-Aldrich), for at least $3 \mathrm{~h}$ at room temperature. Cells were stored at $4{ }^{\circ} \mathrm{C}$ then analysed on an FC500 flow cytometer (Beckman Coulter, Brea, CA, USA). At least 50000 events were recorded per sample and results were statistically analysed. Cellular debris and doublets were excluded from the analysis based on non-linearity on a doublet discrimination plot. Data analysis was performed using Multicycle AV on FCS Express Flow Cytometry Research Edition Version 4 (DeNovo Software, Glendale, CA, USA).

\section{Statistical analysis of data}

Statistical analysis was carried out in GraphPad Prism, Version 6.05 (GraphPad, GraphPad Software Inc) or using Microsoft Excel 2010. A two-sided Student's $t$-test was used to estimate differences between data groups, unless otherwise stated. Data are expressed as mean \pm s.e.m. $P$-values $<0.05$ were considered as statistically significant. The sample sizes were determined by power analyses, based on variation shown in our previous experiments and predicted effect sizes considered to be biological significant. No data were excluded from any analyses and all replicates are true biological replicates. The statistical test used and the sample sizes for individual analyses are provided within the figure legends.

\section{ABBREVIATIONS}

ATM, Ataxia telangiectasia mutated; BUB3, budding uninhibited by benzimidazoles 3 homolog; CDC20, Cell Division Cycle 20; ConA, Concanavalin A; Mad2, mitotic arrest deficient 2; MEFs, murine embryonic fibroblasts; MOMP, mitochondrial outer membrane permeabilization; PLK1I, Polo-Like kinase 1 inhibitor; SAC, spindle-assembly checkpoint.

\section{CONFLICT OF INTEREST}

The authors declare no conflict of interest.

\section{ACKNOWLEDGEMENTS}

We thank staff at the SA Pathology animal resource facility for help in maintaining the mouse strains and members of our laboratory for discussions and useful comments. Funding for this work was provided by the National Health and Medical Research Council project grant (1043057) and a Senior Principal Research Fellowship (1103006) to Sharad Kumar. Loretta Dorstyn was a Cancer Council Research Fellow and Swati Dawar is supported by a UniSA Presidential Award.

\section{AUTHOR CONTRIBUTIONS}

Swati Dawar carried out most experiments and collected data; Yoon Lim carried out $\mathrm{BiFC}$, immunoblotting experiments, clonogenic assays and characterized Casp2 ${ }^{\mathrm{C} 320 S}$ mice; Joseph Puccini generated $\mathrm{Atm}^{-/}, \mathrm{Atm}^{-/-} / \mathrm{Casp2}^{-/-}$lymphoma cells; Joseph Puccini, Melissa White and Paul Thomas helped generate Casp2 $2^{\mathrm{C} 205}$ mice; Lisa Bouchier-Hayes and Douglas R. Green contributed BiFC reagents and advice; Loretta Dorstyn and Sharad Kumar designed and supervised the study, analysed data and wrote the paper. All authors discussed the results and commented on the manuscript.

\section{REFERENCES}

1 Gordon DJ, Resio B, Pellman D. Causes and consequences of aneuploidy in cancer. Nat Rev Genet 2012; 13: 189-203.
2 Hanahan D, Weinberg RA. Hallmarks of cancer: the next generation. Cell 2011; 144: 646-674.

3 Geigl JB, Obenauf AC, Schwarzbraun T, Speicher MR. Defining 'chromosomal instability'. Trends Genet 2008; 24: 64-69.

4 Holland AJ, Cleveland DW. Boveri revisited: chromosomal instability, aneuploidy and tumorigenesis. Nat Rev Mol Cell Biol 2009; 10: 478-487.

5 Castedo M, Perfettini JL, Roumier T, Valent A, Raslova H, Yakushijin K et al. Mitotic catastrophe constitutes a special case of apoptosis whose suppression entails aneuploidy. Oncogene 2004; 23: 4362-4370.

6 Vitale I, Galluzzi L, Castedo M, Kroemer G. Mitotic catastrophe: a mechanism for avoiding genomic instability. Nat Rev Mol Cell Biol 2011; 12: 385-392.

7 Castedo M, Perfettini JL, Roumier T, Andreau K, Medema R, Kroemer G. Cell death by mitotic catastrophe: a molecular definition. Oncogene 2004; 23: 2825-2837.

8 Decordier I, Dillen L, Cundari E, Kirsch-Volders M. Elimination of micronucleated cells by apoptosis after treatment with inhibitors of microtubules. Mutagenesis 2002; 17: 337-344.

9 Giam M, Rancati G. Aneuploidy and chromosomal instability in cancer. Cell Div 2015; 10: 3.

10 Li M, Zhang P. Spindle assembly checkpoint, aneuploidy and tumorigenesis. Cell Cycle 2009; 8: 3440.

11 Baliga BC, Read SH, Kumar S. The biochemical mechanism of caspase-2 activation. Cell Death Differ 2004; 11: 1234-1241.

12 Kumar S. Caspase 2 in apoptosis, the DNA damage response and tumour suppression: enigma no more? Nat Rev Cancer 2009; 9: 897-903.

13 Dorstyn L, Puccini J, Wilson CH, Shalini S, Nicola M, Moore S et al. Caspase-2 deficiency promotes aberrant DNA-damage response and genetic instability. Cell Death Differ 2012; 19: 1288-1298.

14 Ho LH, Taylor R, Dorstyn L, Cakouros D, Bouillet P, Kumar S. A tumor suppressor function for caspase-2. Proc Natl Acad Sci USA 2009; 106: 5336-5341.

15 Yoo BH, Wang Y, Erdogan M, Sasazuki T, Shirasawa S, Corcos L et al. Oncogenic ras-induced down-regulation of pro-apoptotic protease caspase-2 is required for malignant transformation of intestinal epithelial cells. J Biol Chem 2011; 286: 38894-38903.

16 Ho LH, Read SH, Dorstyn L, Lambrusco L, Kumar S. Caspase-2 is required for cell death induced by cytoskeletal disruption. Oncogene 2008; 27: 3393-3404.

17 Manzl C, Peintner L, Krumschnabel G, Bock F, Labi V, Drach M et al. PIDDosomeindependent tumor suppression by Caspase-2. Cell Death Differ 2012; 19: $1722-1732$.

18 Parsons MJ, McCormick L, Janke L, Howard A, Bouchier-Hayes L, Green DR. Genetic deletion of caspase-2 accelerates MMTV/c-neu-driven mammary carcinogenesis in mice. Cell Death Differ 2013; 20: 1174-1182.

19 Puccini J, Dorstyn L, Kumar S. Caspase-2 as a tumour suppressor. Cell Death Differ 2013; 20: 1133-1139.

20 Terry MR, Arya R, Mukhopadhyay A, Berrett KC, Clair PM, Witt B et al. Caspase-2 impacts lung tumorigenesis and chemotherapy response in vivo. Cell Death Differ 2015; 22: 719-730.

21 Puccini J, Shalini S, Voss AK, Gatei M, Wilson CH, Hiwase DK et al. Loss of caspase-2 augments lymphomagenesis and enhances genomic instability in Atmdeficient mice. Proc Natl Acad Sci USA 2013; 110: 19920-19925.

22 Shalini S, Nikolic A, Wilson CH, Puccini J, Sladojevic N, Finnie J et al. Caspase-2 deficiency accelerates chemically induced liver cancer in mice. Cell Death Differ 2016; 23: 1727-1736.

23 Hamanaka R, Smith MR, O'Connor PM, Maloid S, Mihalic K, Spivak JL et al. Polo-like kinase is a cell cycle-regulated kinase activated during mitosis. J Biol Chem 1995; 270: $21086-21091$.

24 Wang Q, Xie S, Chen J, Fukasawa K, Naik U, Traganos F et al. Cell cycle arrest and apoptosis induced by human Polo-like kinase 3 is mediated through perturbation of microtubule integrity. Mol Cell Biol 2002; 22: 3450-3459.

25 Lu B, Mahmud H, Maass AH, Yu B, van Gilst WH, de Boer RA et al. The Plk1 inhibitor BI 2536 temporarily arrests primary cardiac fibroblasts in mitosis and generates aneuploidy in vitro. PLoS One 2010; 5: e12963.

26 Wasch R, Hasskarl J, Schnerch D, Lubbert M. BI_2536 - targeting the mitotic kinase Polo-like kinase 1 (Plk1). Recent Results Cancer Res 2010; 184: 215-218.

27 Miki H, Okada Y, Hirokawa N. Analysis of the kinesin superfamily: insights into structure and function. Trends Cell Biol 2005; 15: 467-476.

28 Kanda T, Sullivan KF, Wahl GM. Histone-GFP fusion protein enables sensitive analysis of chromosome dynamics in living mammalian cells. Curr Biol 1998; 8: 377-385.

29 Brito DA, Rieder CL. Mitotic checkpoint slippage in humans occurs via cyclin B destruction in the presence of an active checkpoint. Curr Biol 2006; 16: 1194-1200.

30 Bouchier-Hayes L, Oberst A, McStay GP, Connell S, Tait SW, Dillon CP et al. Characterization of cytoplasmic caspase-2 activation by induced proximity. $\mathrm{Mol}$ Cell 2009; 35: 830-840. 
31 Guo Y, Srinivasula SM, Druilhe A, Fernandes-Alnemri T, Alnemri ES. Caspase-2 induces apoptosis by releasing proapoptotic proteins from mitochondria. J Biol Chem 2002; 277: 13430-13437.

32 Robertson JD, Enoksson M, Suomela M, Zhivotovsky B, Orrenius S. Caspase-2 acts upstream of mitochondria to promote cytochrome $c$ release during etoposideinduced apoptosis. J Biol Chem 2002; 277: 29803-29809.

33 Shalini S, Dorstyn L, Dawar S, Kumar S. Old, new and emerging functions of caspases. Cell Death Differ 2015; 22: 526-539.

34 Lassus P, Opitz-Araya X, Lazebnik Y. Requirement for caspase-2 in stress-induced apoptosis before mitochondrial permeabilization. Science 2002; 297: 1352-1354.

35 Ren K, Lu J, Porollo A, Du C. Tumor-suppressing function of caspase-2 requires catalytic site Cys-320 and site Ser-139 in mice. J Biol Chem 2012; 287: 14792-14802.

36 Andersen JL, Johnson CE, Freel CD, Parrish AB, Day JL, Buchakjian MR et al. Restraint of apoptosis during mitosis through interdomain phosphorylation of caspase-2. EMBO J 2009; 28: 3216-3227.

37 Mendelsohn AR, Hamer JD, Wang ZB, Brent R. Cyclin D3 activates Caspase 2, connecting cell proliferation with cell death. Proc Natl Acad Sci USA 2002; 99: 6871-6876.

38 Taghiyev AF, Rokhlin OW, Glover RB. Caspase-2-based regulation of the androgen receptor and cell cycle in the prostate cancer cell line LNCaP. Genes Cancer 2011; 2: 745-752.

39 Choi M, Kim W, Cheon MG, Lee CW, Kim JE. Polo-like kinase 1 inhibitor BI2536 causes mitotic catastrophe following activation of the spindle assembly checkpoint in non-small cell lung cancer cells. Cancer Lett 2015; 357: 591-601.

40 Kroemer G, Galluzzi L, Vandenabeele P, Abrams J, Alnemri ES, Baehrecke EH et al. Classification of cell death: recommendations of the Nomenclature Committee on Cell Death 2009. Cell Death Differ 2009; 16: 3-11.

41 Cimini D, Howell B, Maddox P, Khodjakov A, Degrassi F, Salmon ED. Merotelic kinetochore orientation is a major mechanism of aneuploidy in mitotic mammalian tissue cells. J Cell Biol 2001; 153: 517-527.

42 Ganem NJ, Godinho SA, Pellman D. A mechanism linking extra centrosomes to chromosomal instability. Nature 2009; 460: 278-282.

43 Dobles M, Liberal V, Scott ML, Benezra R, Sorger PK. Chromosome missegregation and apoptosis in mice lacking the mitotic checkpoint protein Mad2. Cell 2000; 101: 635-645.

44 Michel LS, Liberal V, Chatterjee A, Kirchwegger R, Pasche B, Gerald W et al. MAD2 haplo-insufficiency causes premature anaphase and chromosome instability in mammalian cells. Nature 2001; 409: 355-359.
45 Shalini S, Dorstyn L, Wilson C, Puccini J, Ho L, Kumar S. Impaired antioxidant defence and accumulation of oxidative stress in caspase-2-deficient mice. Cell Death Differ 2012; 19: 1370-1380.

46 Zhang Y, Padalecki SS, Chaudhuri AR, De Waal E, Goins BA, Grubbs B et al. Caspase-2 deficiency enhances aging-related traits in mice. Mech Ageing Dev 2007; 128: 213-221.

47 Palmisiano ND, Kasner MT. Polo-like kinase and its inhibitors: ready for the match to start? Am J Hematol 2015; 90: 1071-1076.

48 Decordier I, Cundari E, Kirsch-Volders M. Survival of aneuploid, micronucleated and/or polyploid cells: crosstalk between ploidy control and apoptosis. Mutat Res 2008; 651: 30-39.

49 Peterson SE, Yang AH, Bushman DM, Westra JW, Yung YC, Barral S et al. Aneuploid cells are differentially susceptible to caspase-mediated death during embryonic cerebral cortical development. J Neurosci 2012; 32: 16213-16222.

50 Kaufmann T, Tai L, Ekert PG, Huang DC, Norris F, Lindemann RK et al. The BH3-only protein bid is dispensable for DNA damage- and replicative stress-induced apoptosis or cell-cycle arrest. Cell 2007; 129: 423-433.

51 O'Reilly LA, Ekert P, Harvey N, Marsden V, Cullen L, Vaux DL et al. Caspase-2 is not required for thymocyte or neuronal apoptosis even though cleavage of caspase-2 is dependent on both Apaf-1 and caspase-9. Cell Death Differ 2002; 9: 832-841.

52 Dorstyn L, Kumar S. Caspase-2 protocols. Methods Mol Biol 2014; 1133: 71-87.

53 Parsons MJ, Bouchier-Hayes L. Measuring initiator caspase activation by bimolecular fluorescence complementation. Cold Spring Harb Protoc 2015; 2015: pdb prot082552.

54 Belkhiri A, Zhu S, Chen Z, Soutto M, El-Rifai W. Resistance to TRAIL is mediated by DARPP-32 in gastric cancer. Clin Cancer Res 2012; 18: 3889-3900.

(c) (1) This work is licensed under a Creative Commons AttributionNonCommercial-ShareAlike 4.0 International License. The images or other third party material in this article are included in the article's Creative Commons license, unless indicated otherwise in the credit line; if the material is not included under the Creative Commons license, users will need to obtain permission from the license holder to reproduce the material. To view a copy of this license, visit http:// creativecommons.org/licenses/by-nc-sa/4.0/

(c) The Author(s) 2017

Supplementary Information accompanies this paper on the Oncogene website (http://www.nature.com/onc) 